\title{
Logística reversa no comércio eletrônico: um estudo de caso
}

\section{Reverse logistics in the e-commerce: a case study}

\author{
Ana Carolina de Araujo ${ }^{1}$ \\ Érica Mayumi Matsuoka ${ }^{1}$ \\ July Ellen Ung' ${ }^{1}$ \\ Wilson de Castro Hilsdorf ${ }^{2}$ \\ Mauro Sampaio²
}

\begin{abstract}
Resumo: A logística reversa ganha importância cada vez maior tanto no meio acadêmico quanto entre os profissionais de supply chain, não só por ser um dos instrumentos para a prática da sustentabilidade, como também por seu papel estratégico em muitos segmentos econômicos. Diversos trabalhos mostram como uma logística reversa eficiente pode diminuir custos e propiciar vantagem competitiva às empresas. Da mesma forma, o comércio eletrônico vem apresentando crescimento expressivo em muitos países e, por sua própria natureza apresenta taxas de retorno muito maiores que o comércio tradicional. Contudo, apesar da importância da operação de logística reversa para o comércio eletrônico, não se encontram trabalhos que explorem esse tema na literatura. O objetivo deste trabalho é descrever o processo de logística reversa do maior varejista virtual do mercado brasileiro, mostrando sua evolução, analisando seu desempenho e identificando suas principais deficiências. Conclui-se com a apresentação de sugestões para melhorias e implantação de um sistema mais eficiente.
\end{abstract}

Palavras-chave: Logística reversa. Comércio eletrônico.

\begin{abstract}
Reverse logistics has gained increasing importance among researchers and supply chain professionals not only for being one of the tools for sustainability, but also for its strategic role in many economic sectors. Several studies have shown how an efficient reverse logistics can reduce costs and provide competitive advantage to companies. Likewise, there has been a significant growth of electronic commerce in many countries, which has much higher return rates than those of traditional trade. Nevertheless, despite the importance of reverse logistics in electronic commerce, there are no studies addressing this topic in the literature. The aim of this paper is to describe the reverse logistics process of the largest online retailer in the Brazilian market by showing its development, analyzing its performance, and identifying its major deficiencies. Some suggestions for the improvement and implementation of a more efficient system are made
\end{abstract}

Keywords: Reverse logistics. E-commerce.

\section{Introdução}

A logística reversa é um assunto cada vez mais popular na literatura de gestão de redes de suprimentos (ROGERS; TIBBEN-LEMBKE, 2001; STOCK; MULKI, 2009; CORREA, 2010) e foco de pesquisa de vários autores (LEITE, 2009; MARTINS, 2005), tanto em revistas profissionais como em periódicos acadêmicos. O Council of Supply Chain Management Professionals - CSCMP (2010) define a logística reversa como

[...] um segmento especializado da logística que foca o movimento e o gerenciamento do fluxo reverso de produtos e materiais após a venda e entrega ao consumidor. Inclui os processos de produtos retornados para reparo e/ou reembolso financeiro [...].
O tema já foi estudado na literatura sobre diferentes perspectivas: os benefícios da adoção de uma estrutura de logística reversa (LEITE, 2009), o papel estratégico da logística reversa para obter vantagem competitiva (ROGERS; TIBBEN-LEMBKE, 2001), entre outros. Segundo Mermelstein (2006) apud Jack, Powers e Skinner (2010, p. 229):

[...] $92 \%$ dos consumidores, muito provavelmente comprarão novamente [...] se o processo de retorno for conveniente [...] por outro lado, $82 \%$ muito provavelmente não o fariam se o processo de retorno for inconveniente.

Apesar de sua importância, a logística reversa do comércio eletrônico (LReC) é um tema pouco

\footnotetext{
${ }^{1}$ Engenharia de Produção, Centro Universitário da FEI, CEP 09850-901, São Bernardo do Campo, SP, Brasil

2 Programa de Mestrado em Engenharia Mecânica, Centro Universitário da FEI, Av. Humberto de Alencar Castelo Branco, 3972 , CEP 09850-901, São Bernardo do Campo, SP, Brasil, e-mail: wicastro@ fei.edu.br; msampaio@ fei.edu.br
} 
explorado. Uma pesquisa na Scielo, com o uso da palavra-chave "logística reversa", cobrindo o período de 1999 a 2012 resultou em apenas sete referências, mas nenhuma sobre a logística reversa do comércio eletrônico brasileiro, fato esse incoerente com a importância crescente desse segmento na economia. No Brasil, o segmento vem registrando crescimento da ordem de $30 \%$ ao ano nos últimos tempos (ALBERTIN, 2010).

A LReC é considerada um processo mais oneroso que a logística reversa do varejo tradicional, podendo representar até $6 \%$ da receita de um varejista e até $4 \%$ do custo logístico de um fabricante (LAMBERT, 2002). Nos Estados Unidos, a taxa de retorno do mercado eletrônico é estimada em $37 \%$ das vendas e o valor de revenda entre $10 \%$ a $20 \%$ do custo médio de venda (LAMBERT, 2008). No Brasil, estes números são desconhecidos, assim como os motivos de devolução, taxa de recuperação e padrão de revenda. Tendo em vista essa lacuna, esta pesquisa pretende contribuir para revelar alguns desses aspectos.

A falta de conhecimento do processo de LReC gera problemas variados, tais como: processos de LReC deficitários, pouca troca de informações entre diferentes setores, falta de difusão do conhecimento, pequena participação da comunidade acadêmica no desenvolvimento do setor.

O objetivo desta investigação é descrever e avaliar o processo de logística reversa do maior varejista virtual do mercado brasileiro, que representa aproximadamente $40 \%$ das receitas do comércio eletrônico nacional. Este trabalho avalia o processo, desde a retirada de itens comercializados e recusados pelos consumidores no pós-venda do comércio eletrônico, passando pelo processo de recaptura de valor até a determinação de uma disposição apropriada dos produtos para varejistas e fabricantes. Os objetivos específicos da pesquisa são: identificar as mudanças estratégicas realizadas na empresa nos últimos anos, os problemas e soluções encontrados, as estatísticas do processo $\mathrm{LReC}$ e as tendências futuras para o setor.

Resumidamente, o artigo pretende responder às seguintes questões de pesquisa:
- Como evoluíram os processos de logística reversa de uma das principais empresas do comércio eletrônico brasileiro nos últimos anos?

- Qual a taxa de retorno e os motivos de devolução em uma das principais empresas de comércio eletrônico no Brasil?

- Quais as principais deficiências no processo de logística reversa desta empresa?

Para responder a essas perguntas, o texto está dividido em cinco seções. A primeira é a introdução, a segunda trata da revisão da literatura sobre o tema logística reversa no comércio eletrônico. A terceira parte apresenta a metodologia utilizada, a quarta exibe o estudo de caso e, por fim, a última seção apresenta as conclusões da pesquisa.

\section{Revisão da literatura}

A logística do comércio eletrônico demanda diferentes práticas operacionais a fim de atender às necessidades desse tipo de consumidor. McCullough (1999) identifica as principais diferenças entre a logística tradicional e a logística do comércio eletrônico, conforme mostra o Quadro 1.

Novaes (2007) confirma que uma diferença central é o fluxo de produtos, que não é mais processado em caixas e sim em unidade de estocagem, o que exige a execução de operações com cuidados adicionais. A expectativa dos consumidores em relação à entrega do produto também é outro fator que muda, pois ele espera entrega quase imediata, tornando o planejamento logístico muito mais dinâmico do que na logística tradicional que foca na transferência de grandes lotes de produtos. Outra prática diferenciada destacada por Novaes (2007) é a imprevisibilidade da demanda, gerando situações de atrasos nas entregas, excesso de ruptura de produto no estoque, reclamações e comprometimento da imagem do varejista virtual junto aos consumidores.

Para um planejamento adequado da operação logística do comércio eletrônico, é necessário levar em conta os seguintes aspectos (ROGERS; TIBBENLEMBKE, 1999):

Quadro 1. Logística tradicional X logística comércio eletrônico.

\begin{tabular}{|l|l|l|}
\hline \multicolumn{1}{|c|}{ Operações } & \multicolumn{1}{c|}{ Logística tradicional } & \multicolumn{1}{c|}{ Logística do comércio eletrônico } \\
\hline Tipo de envio & Grande volume & Pequeno volume \\
\hline Consumidor & Conhecido & Desconhecido \\
\hline Tipo de demanda & Empurrada & Puxada \\
\hline Fluxo de pedidos/estoques & Unidirecional & Bidirecional \\
\hline Valor médio do pedido & Mais de US\$ 1000 & Menos \$100 \\
\hline Destinos & Concentrados & Altamente dispersos \\
\hline Demanda & Estável, consistente & Altamente instável, fragmentada \\
\hline Responsabilidade & Com apenas um vínculo & Por meio da totalidade da Supply chain \\
\hline
\end{tabular}

Fonte: McCullough (1999). 
- Gerenciamento dos estoques: é importante que a informação de estoque disponível no site de vendas esteja completamente alinhada com sua real disponibilidade, portanto faz-se necessária a integração do sistema de controle de estoque com a solução do comércio eletrônico. Com isso reduzem-se substancialmente os riscos de falta de produtos no estoque;

- Gerenciamento das entregas: normalmente o serviço de transporte e entrega dos produtos é feito por empresas terceirizadas e especializadas no mercado, como, por exemplo, os Correios (e-Sedex). Qualquer que seja o operador logístico é necessário um sistema que permita a rastreabilidade do produto pelo cliente. Da mesma forma, o operador logístico deve ter condições de realizar a logística reversa, quando ocorre a devolução dos produtos por diversas razões que serão citadas mais adiante;

- Gerenciamento do ciclo de suprimento: para haver uma boa sincronia com os fornecedores nos ciclos de processos de suprimentos, é necessário informatizá-los de modo que, sempre que o nível de estoque atingir uma determinada quantidade mínima, seja disparado automaticamente o pedido para o fornecedor. A atualização do sistema deve ser feita frequentemente para que as informações relacionadas aos estoques estejam sempre alinhadas; e

- Logística reversa: Existem diferenças significativas entre a logística direta e a logística reversa do comércio eletrônico, conforme mostra o Quadro 2.

A logística reversa do comércio eletrônico precisa ser eficiente de forma a definir o destino final do produto o mais rápido possível. Existem perdas consideráveis do valor do produto retornado em função do tempo de processamento, conforme Figura 1. O custo de demora é acentuado, tanto para itens que não necessitam de recuperação para serem revendidos, como para itens que precisam ser recuperados.

A Figura 1 mostra que tanto os produtos que não necessitam de recuperação quanto os produtos que sofrem uma tratativa de recuperação perdem valor ao longo do tempo na logística reversa, devido principalmente ao longo tempo entre a recepção do produto e sua efetiva revenda.

As empresas do comércio eletrônico têm preocupação com a logística reversa pelo fato de seus lucros estarem vinculados ao marketing estratégico e sua imagem depender da satisfação do cliente durante o processo de comercialização. Essa é uma das razões apontadas por Krumwiede e Sheu (2002) que incentivam tais organizações a adotarem políticas liberais e flexíveis de devolução de mercadorias. Tal comportamento pró-ativo também ajuda as empresas a adquirir experiência em gestão eficiente de custos de alienação, além de criar novas oportunidades de negócios lucrativos, uma vez que elas podem entrar no mercado secundário e vender produtos recondicionados (SCHULTMANN; ZUMKELLER, 2006). Em complemento, a imagem liberal positiva contribui para o aumento das vendas (GEORGIADIS; VLACHOS, 2004).

Outra razão levantada por Leite (2009) para maior preocupação com a logística reversa por parte dos varejistas virtuais é a pressão da legislação, que permite ao consumidor rejeitar o produto por diversas razões, dentro de um prazo de sete dias a contar da data de recebimento, caracterizando, dessa forma, um canal sujeito a níveis de devolução elevados.

Os motivos para devoluções podem ser: razões comerciais, erros no processamento dos pedidos, garantias dadas pelo fabricante, defeitos ou falhas de funcionamento, avarias no transporte, o fim da validade do produto, estoques excessivos nas transportadoras, problemas de qualidade, defeitos ou,

Quadro 2. Diferenças entre a logística direta e a reversa do comércio eletrônico.

\begin{tabular}{|l|l|}
\hline \multicolumn{1}{|c|}{ Logística direta } & \multicolumn{1}{c|}{ Logística reversa } \\
\hline Qualidade do produto uniforme & Qualidade do produto não uniforme \\
\hline Trajeto previsível dos produtos & Trajeto e rotinas pouco previsíveis \\
\hline Custos mais facilmente entendidos & Custos pouco entendidos \\
\hline Precificação uniforme & Precificação muito pouco uniforme \\
\hline Alta acurácia do inventário & Baixa acurácia do inventário \\
\hline Ciclo de vida administrável & Ciclo de vida pouco administrável \\
\hline Aspectos financeiros dominados & Aspectos financeiros pouco previsíveis \\
\hline Clientes definidos & Clientes pouco definidos \\
\hline Negociações claras & Negociações menos diretas \\
\hline Visibilidade transparente & Visibilidade pouco transparente \\
\hline
\end{tabular}

Fonte: Rogers e Tibben-Lembke (1999). 


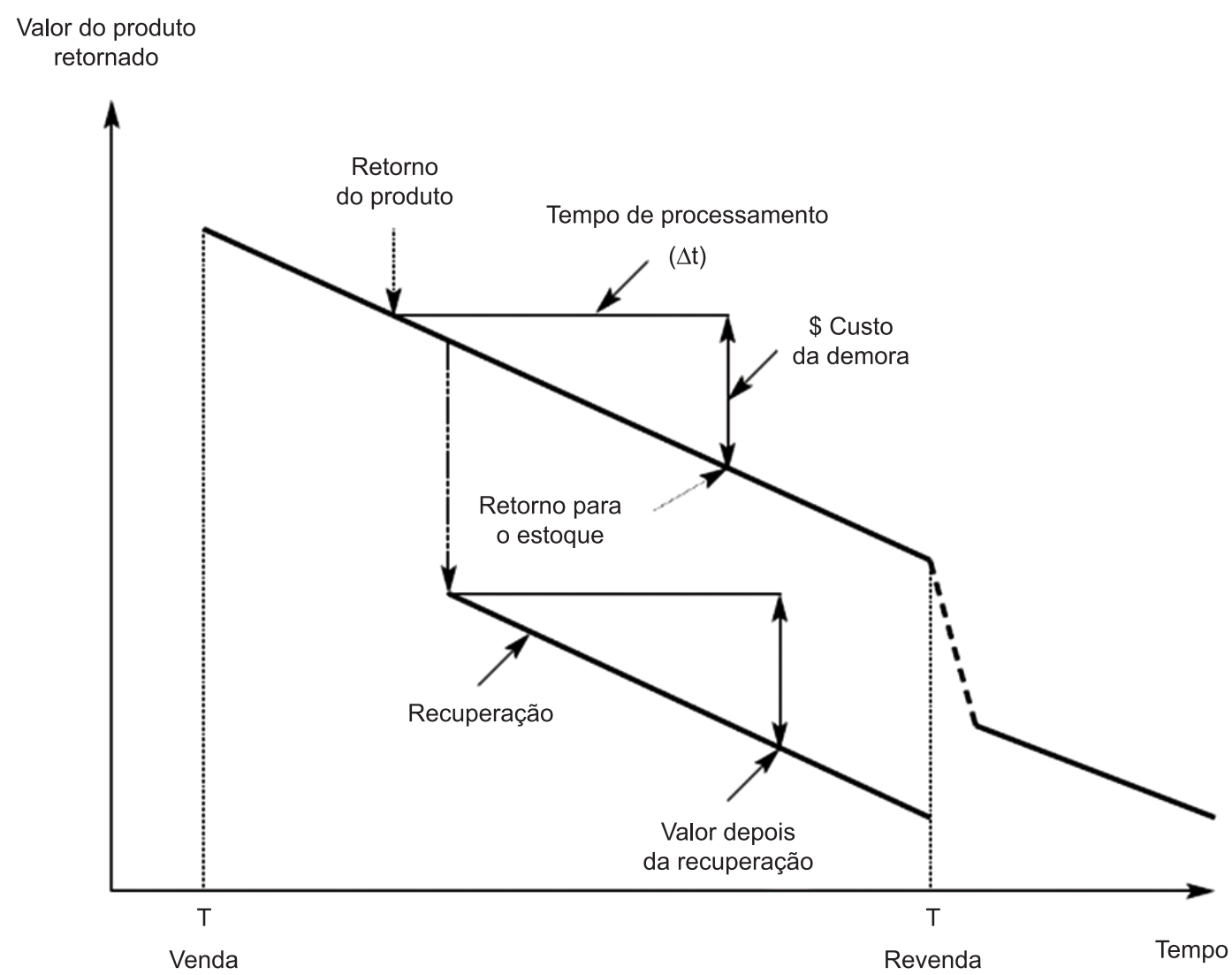

Figura 1. Perdas de valor em função do tempo transcorrido entre a venda e a revenda de um produto retornado. Fonte: Rogers e Tibben-Lembke (1999).

simplesmente, um desacordo com as expectativas do cliente (STOCK, 1998; ROGERS; TIBBEN-LEMBKE, 1999; LEITE, 2009).

Segundo Knebel (2009), a melhoria dos processos de logística reversa já resultou na redução do tempo médio de retorno dos produtos do comércio eletrônico de vinte para sete dias. Aos poucos, a logística reversa eficiente está se transformando em uma ferramenta de fidelização e valorização do cliente que, ao ter uma boa experiência com a devolução do produto por uma eventual necessidade, fica mais suscetível à recompra pela internet (KNEBEL, 2009).

Agrawal (2012) apresenta os principais destinos dos produtos retornados sem consumo e esses estão listados a seguir.

- Reparações, consertos e remanufatura - No caso de necessidade, os produtos de retorno serão destinados ao reparo e/ou conserto e poderão ser comercializados no mercado secundário. Caso não tenham defeitos, poderão ser negociados no mercado primário. O processo de remanufatura se dará quando os componentes dos bens retornados puderem ser recuperados e encaminhados ao mercado secundário. Muitas empresas de grande porte utilizam o sistema de desmontagem de componentes e revisão para alimentar o seu mercado de peças de reposição, recuperando valores importantes. No entanto, este procedimento não é comum no comércio eletrônico;

- Leilão ou descontos na revenda - O destino de leilões ocorre quando o bem retornado apresenta-se sem condições de funcionamento para a utilidade de projeto e existe valor de uso em seus componentes. Esta operação é normalmente realizada por empresas que arrematam os produtos nestas condições e os componentes são enviados ao mercado secundário de peças ou subconjuntos, ou antes, passando por processo de remanufatura;

- Desmontagem e Reciclagem - Os subconjuntos ou partes da estrutura dos bens são comercializados com empresas especializadas na reciclagem dos materiais constituintes destes produtos. A identidade original do produto é perdida neste processo;

- Redistribuição - Alguns produtos de retorno normalmente possuem condições gerais de 
serem reenviados ao mercado primário, ou seja, o mercado original, com a marca do fabricante e por meio de redistribuição;

- Doação - O caso de doações é normalmente um destino de produtos retornados quando existe interesse de fixação de imagem por parte do fabricante e normalmente associado a produtos com certo grau de obsolescência. Caso muito comum no setor de computadores que apresentam vida média útil muito curta, mas que apresentam interesse no mesmo país ou em outros países mais necessitados;

- Geração de Energia - Alguns produtos, como alimentos e bebidas, não podem ser recuperados ou reciclados, mas podem ser convertidos em energia;

- Política de "zero retorno"- Alguns fabricantes adotam a política de não aceitar retornos de seus produtos, mas autorizam seus varejistas e distribuidores a encaminhar os produtos para destinos predeterminados; e

- Aterros/Incineração - Não havendo nenhuma outra solução para agregar valor de qualquer natureza ao produto retornado ou de suas partes ou materiais, eles são destinados a aterros sanitários ou ao processo de incineração, dependendo das peculiaridades de cada país ou região.

Kokkinaki et al. (1999) identificaram três modelos de reposição de produtos remanufaturados no comércio eletrônico: o marketplace eletrônico. São sites especializados na comercialização de produtos novos e usados pela internet, há também sites que usam a internet para oferecer exclusivamente peças usadas ou equipamentos remanufaturados e a solução completa de logística reversa que incorpora a coleta, seleção, recuperação e redistribuição de produtos recuperados. Estes modelos são apresentados na Figura 2.

O caso da logística reversa do comércio eletrônico é mais aderente ao terceiro modelo de Kokkinaki et al. (1999), já que inclui todas as fases do processo, coleta, seleção, recuperação e redistribuição dos produtos, o que permite a recuperação de valor.

Apesar de a literatura considerar importante e relevante o processo logístico reverso, poucos estudos foram realizados até o momento sobre os detalhes

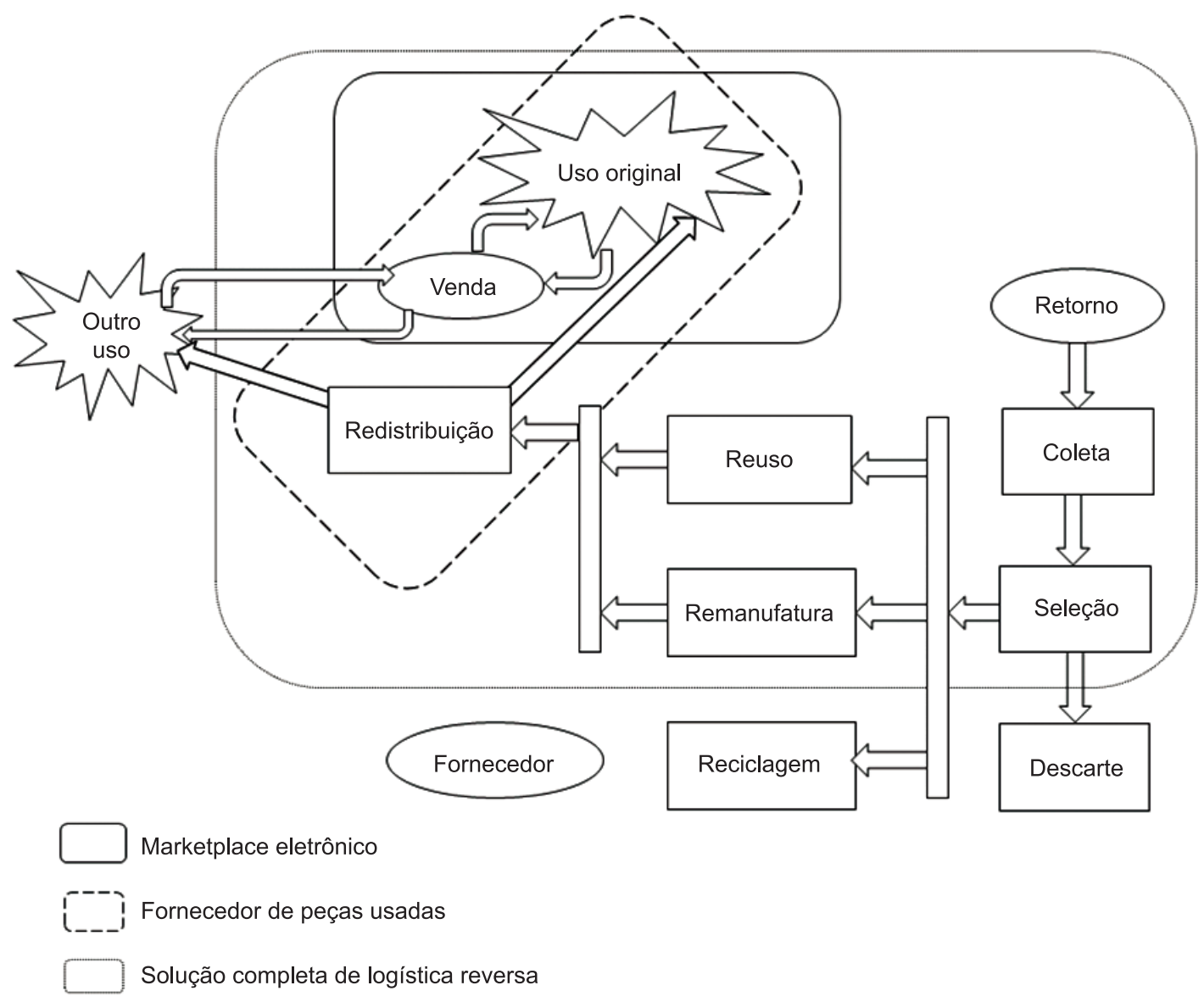

Figura 2. Modelos de reposição de produtos remanufaturados no comércio eletrônico. Fonte: Kokkinaki et al. (1999). 
e as etapas da logística reversa de uma empresa de comércio eletrônico e as dificuldades encontradas neste processo.

\section{Metodologia}

O propósito da pesquisa foi estudar um fenômeno emergente inserido no contexto do mundo real, o processo de $\mathrm{LReC}$, evento contemporâneo sobre o qual o pesquisador não tem controle sobre os acontecimentos. Neste contexto, a metodologia recomendada por vários autores (EISENHARDT, 1989; ELLRAM, 1996; YIN, 2003; entre outros) é o estudo de caso. O conhecimento disponível sobre o fenômeno de interesse é escasso, observado pelo baixo índice de publicações sobre o assunto. Nesse caso, a pesquisa exploratória é essencial para desenvolver e prover novas ideias e descobertas.

De acordo com Yin (2003), existem dois tipos de estudo de caso: o caso único, em que a unidade de análise é um caso apenas; e os estudos multicasos, em que vários casos são analisados de forma a permitir o estabelecimento de comparações. O autor também classifica o estudo de caso único em holístico ou incorporado. O tipo holístico possui uma unidade de análise sendo considerada em determinado contexto; já o incorporado possui mais de uma unidade de análise para cada caso, ou seja, existem subunidades de análise.

Yin (2003) estabelece ainda outra classificação do estudo de caso quanto ao objetivo da pesquisa, que pode ser: descritivo, quando descreve o fenômeno dentro de seu contexto; exploratório, quando trata com problemas pouco conhecidos, objetivando definir hipóteses ou proposições para futuras pesquisas; e explanatório, quando possui o intuito de explicar relações de causa e efeito a partir de uma teoria.

Assim, de acordo com os parâmetros de Yin (2003), o presente estudo apresenta-se como um caso único, incorporado e do tipo descritivo, principalmente pela natureza rara de investigar os processos de logística reversa de uma importante empresa de comércio eletrônico. Este caso serve a um propósito revelador, pois o pesquisador teve a chance de observar um fenômeno anteriormente não acessível à investigação científica.

\subsection{Proposições}

Como é coerente em estudos de casos, não é necessário especificar hipóteses formais antes de iniciar o estudo. Entretanto, de acordo com Yin (2003), é aceitável a apresentação de proposições, como respostas antecipadas às questões de pesquisa. Este procedimento ajuda o pesquisador a direcionar o trabalho de coleta de informações.

Proposição 1 - O processo da logística reversa de uma empresa de comércio eletrônico sofre modificações com o aumento do volume de vendas para lidar com o aumento de complexidade.

Proposição 2 - A taxa de retorno de uma empresa de comércio eletrônico no Brasil é inferior à taxa de retorno de uma empresa de comércio eletrônico de participação de mercado semelhante em países desenvolvidos. Os produtos retornam, devido, principalmente, a defeitos dos fabricantes e a avarias do varejista durante o processo de logística direta.

Preposição 3 - As principais deficiências da logística reversa são: elevado tempo de recuperação dos produtos avariados e perdas financeiras decorrentes desta demora.

\subsection{Unidade de análise}

A unidade de análise para o presente estudo de caso foi o processo de logística reversa de um importante representante do mercado brasileiro de comércio eletrônico no período de janeiro de 1999 a junho de 2012.

\subsection{Seleção do caso}

Num estudo de caso único, a escolha da amostra adquire um sentido muito particular (YIN, 2003). A escolha da empresa estudada é sempre intencional, baseando-se em critérios pragmáticos e teóricos, em detrimento de critérios probabilísticos, procurando as variações máximas e não a uniformidade. Neste trabalho, optou-se pela estratégia de seleção de um caso típico: a operação de logística reversa do maior varejista do mercado eletrônico brasileiro. Como a venda pela internet é um fenômeno contemporâneo, estudar a logística reversa de seu maior representante é um direcionador importante para as demais empresas em crescimento de vendas, que provavelmente podem enfrentar problemas similares no futuro.

A empresa de comércio eletrônico estudada é uma companhia global do varejo com atuação por meio de diversos canais de distribuição - televendas (com anúncios por televisão e catálogos), catálogos, quiosques e Internet. Esta empresa é um dos principais varejistas brasileiro, sendo responsável por quase $40 \%$ de todo o mercado de varejo eletrônico nacional.

\subsection{Protocolo de coleta de dados}

Diversos autores (EISENHARDT, 1989; ELLRAM, 1996; YIN, 2003) defendem que a coleta de dados qualitativos deve ser baseada em múltiplas fontes de evidência, mas sempre convergindo para o mesmo conjunto de fatos e descobertas. O estudo de caso foi realizado por meio de entrevistas em profundidade com diferentes profissionais da empresa atuantes no processo da logística reversa, além de visitas ao escritório e aos Centros de Distribuição para coleta de informações e observação direta dos processos. 
O Quadro 3 mostra os respondentes que foram entrevistados durante o estudo de caso.

\section{Resultados}

Os resultados da pesquisa sobre a logística reversa do varejista estudado são mostrados na seguinte sequência: inicialmente, são apresentadas estatísticas básicas da logística reversa do varejista, como índices de retorno, tipos de produtos que retornam e os motivos de devolução. Na sequência, as diferentes fases do processo de logística reversa são discriminadas, relatando as principais dificuldades encontradas durante o processo e as vantagens e desvantagens resultantes das diferentes tratativas ou tratamentos para recuperação do item avariado. Finalmente, são analisados de forma cruzada os diferentes modelos de logística reversa adotados.

\subsection{Taxa de retorno}

A empresa varejista virtual recebe mais de 1,4 milhões de pedidos mensais com média de 1,6 itens por pedido. Os produtos são enviados ao consumidor que eventualmente retornam os produtos para o canal de logística reversa em função de algum problema identificado.

De acordo com o Código de Defesa do Consumidor (CDC), produtos comprados pela internet podem ser trocados no prazo de sete dias se o cliente não ficar satisfeito e/ou se o produto não estiver conforme o anunciado.

O consumidor pode desistir do contrato, no prazo de sete dias a contar de sua assinatura ou do ato de recebimento do produto ou serviço, sempre que a contratação de fornecimento de produtos e serviços ocorrer fora do estabelecimento comercial, isto é, por meio da internet, de telefone ou de catálogos de vendas (BRASIL, 2011).

Se a empresa de comércio eletrônico não concordar com a devolução, o cliente pode entrar em contato com a Fundação de Proteção e Defesa do Consumidor (PROCON), que irá intermediar as negociações entre as duas partes. De acordo com o PROCON, os principais motivos de reclamações de produtos adquiridos por comércio eletrônico são os seguintes:

- Não entrega/demora na entrega do produto;

- Garantia (abrangência, cobertura, etc.);

- Produto entregue com danos, defeitos; e

- Desistência da compra (cancelamento do pedido).

O recebimento médio de produtos retornados é da ordem de 1,8 mil peças por dia ou 7,0 milhões por mês. Essa taxa de retorno corresponde a algo entre 3\% e $4 \%$ do total do faturamento da empresa de comércio eletrônico. Esse índice de retorno do mercado brasileiro é muito inferior aos divulgados e publicados sobre o retorno do comércio eletrônico norte-americano, estimado em 37\% (LAMBERT, 2002). Os entrevistados afirmam que os consumidores brasileiros são menos exigentes, já as políticas norte-americanas são liberais e os processos de logística reversas mais acessíveis. $O$ varejista virtual estudado não representa todo o mercado virtual, mas é responsável por $40 \%$ do mercado eletrônico brasileiro, sendo, portanto, um representante importante do mercado.

Segundo o gerente entrevistado, responsável pela logística reversa do varejista

estima-se que cerca de R $\$ 70$ milhões em produtos retornados ficam parados nos estoques da empresa - sendo boa parte apenas com a caixa aberta ou com pequenas avarias de transporte -, porque elas não encontram alternativas para tratar este produto.

A Figura 3 apresenta os valores dos fluxos macros de entradas e saída médios do sistema de logística reversa do operador logístico. Os produtos que retornam do consumidor representam 100\% das entradas. Depois de avaliados pelo processo de logística reversa, os produtos são enviados (se necessário) para conserto em diferentes assistências técnicas do fornecedor e depois retornam novamente para o Centro de Distribuição da logística reversa. O produto passa uma única vez pela assistência técnica; quando retorna, recebe apenas três tratativas: retorno ao estoque, saldão ou sucata. Outro destino possível é a devolução direta ao fornecedor, quando o fornecedor faz a revisão de seus produtos no próprio $\mathrm{CD}$ da reversa.

Quadro 3. Relação de entrevistados.

\begin{tabular}{|l|l|}
\hline \multicolumn{1}{|c|}{ Empresa } & \multicolumn{1}{c|}{ Função } \\
\hline Varejista & Gerente da logística reversa da empresa estudada \\
\hline Operador logístico & Supervisor de operação \\
& Gerente da logística reversa solução \\
& Gerente operacional da logística reversa \\
& Gerente do segmento de Consumer \& E-commerce \\
\hline
\end{tabular}

Fonte: Autores. 


\subsection{Principais famílias de produtos retornados}

Os produtos retornados podem ser classificados em famílias, de acordo com suas respectivas aplicações. O retorno está concentrado em poucas famílias, como mostrado na Figura 4, sendo que sete delas representam $80 \%$ do valor financeiro de retornos. A principal família de produtos retornados é a família de informática, representando $33 \%$ do total.

\subsection{Principais causas dos produtos retornados}

Os motivos de retornos foram capturados na linha de frente do pós-venda (SAC). Em $49 \%$ dos casos, conforme Figura 5, os clientes alegam defeito nos produtos. Em $26 \%$ dos casos, os consumidores alegam arrependimento da compra e/ou não atendimento às suas expectativas. Foi constatado ainda que outros diversos problemas associados ao processo logístico, denominados na estatística como falhas da logística

Fluxo de entrada

Fluxo de saída

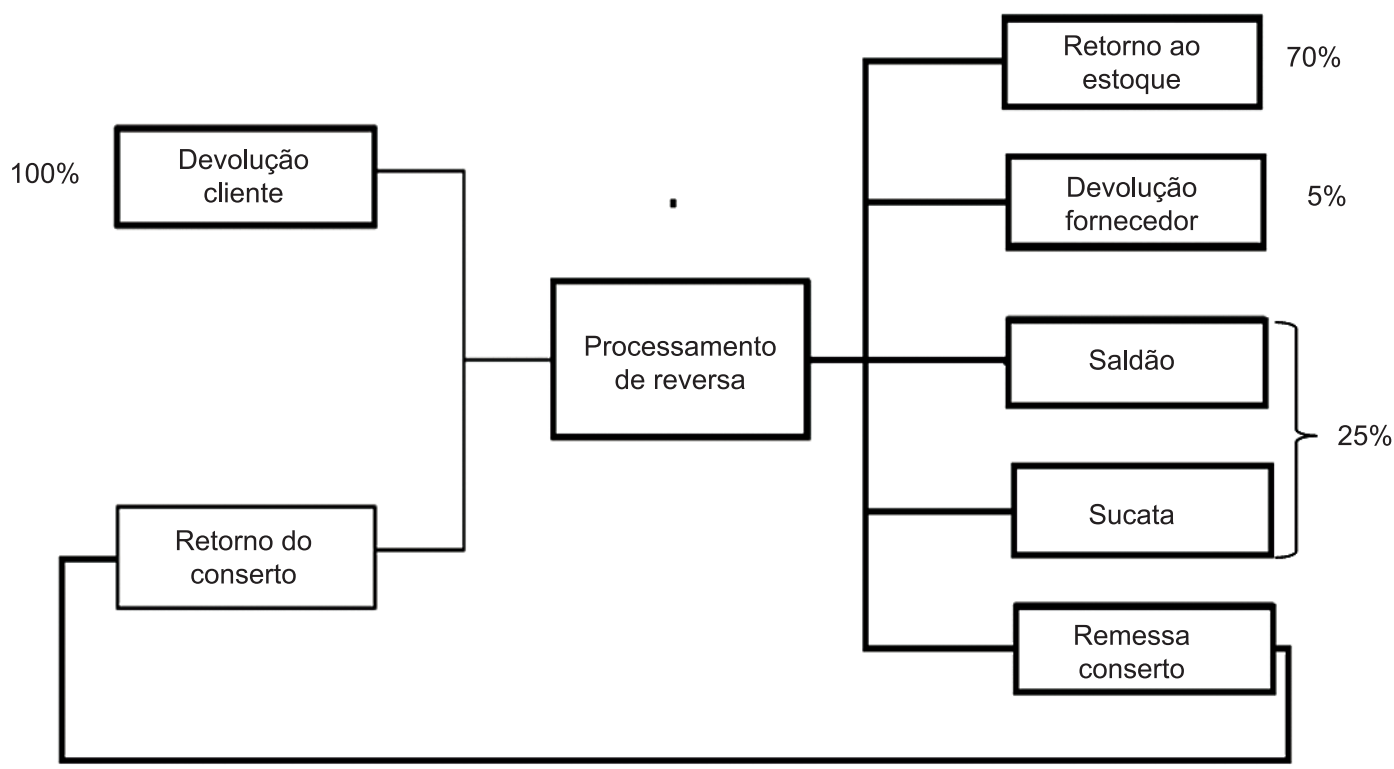

Figura 3. Fluxos macros de entrada/saída. Fonte: a empresa.

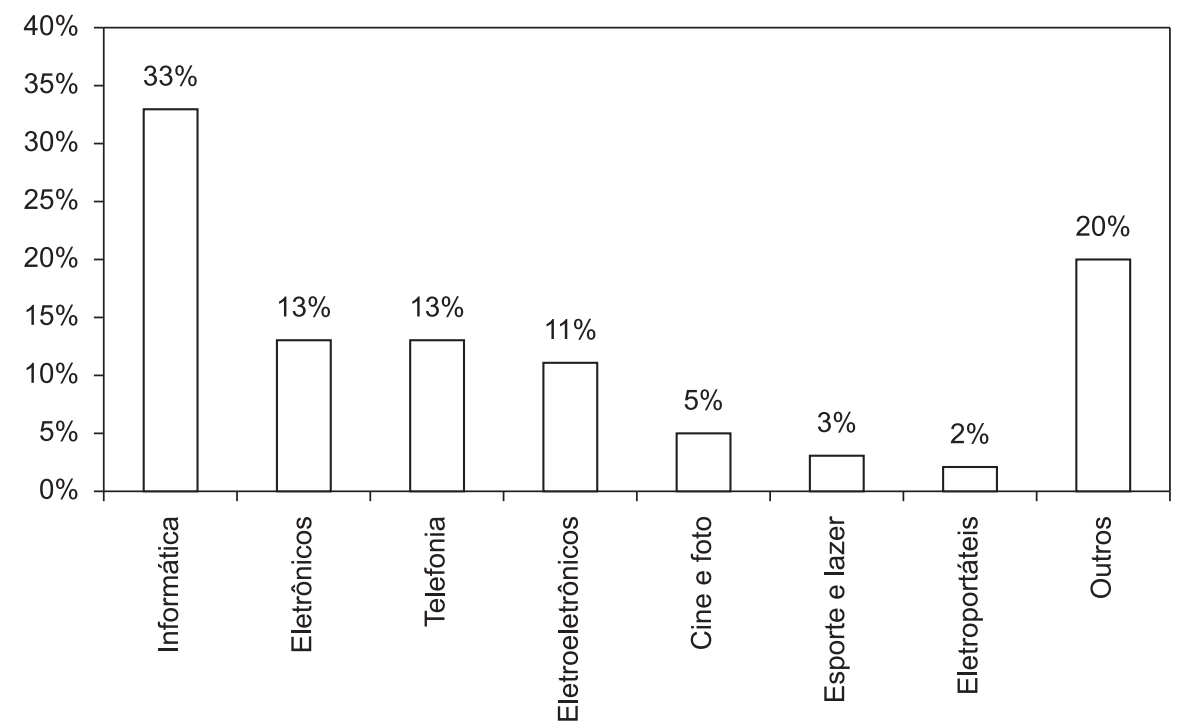

Figura 4. Principais famílias de produtos retornados. Fonte: A empresa. 
do varejista (25\%), também ocasionam muitos retornos. Os problemas típicos das falhas da logística do varejista são: entrega do produto errado (7\%); avarias (7\%); atrasos no envio (3\%); falta de peças (2\%); voltagem errada (1\%); entre outros.

Porém, há também a análise dos motivos de retorno segundo a perspectiva do varejista, a qual constata que muitos dos produtos que retornam por alegação de defeitos, na verdade não os apresentam de fato. A Figura 5 mostra os motivos de devoluções alegados pelos consumidores de forma agrupada e os compara com a perspectiva do fornecedor.

Conforme dados da Figura 5, em 49\% das devoluções, o consumidor afirma que o produto está com defeito, porém, após análise técnica, foi constatado que apenas 5\% do total realmente apresenta algum defeito. $\mathrm{O}$ varejista alega que esse problema ocorre devido à instalação incorreta dos equipamentos, falta de conhecimento da operação do produto, peças montadas inadequadamente, etc.

Resumidamente, constata-se que $70 \%$ dos produtos retornados pelo canal de logística reversa não apresentam quaisquer problemas técnicos e retornam diretamente para os estoques de revenda.

\subsection{Processos de logística reversa do varejista}

Este trabalho relata as diferentes fases do processo de logística reversa da empresa estudada, conforme segue:

- Fase 1 (1999 a 2010): modelo de gestão próprio do varejista;

- Fase 2 (2010 a 2011): a operação de logística reversa terceirizada para um operador logístico nacional; e
- Fase 3 (a partir de 2012): novo modelo de logística reversa adotado pelo operador logístico, que inclui a atividade de revenda de produtos recuperados ao consumidor final.

O processo de logística reversa apresentou várias modificações em relação à fase inicial do comércio eletrônico no Brasil, visando especialmente ganhos de produtividade da operação. A seguir, são expostas as particularidades de cada modelo adotado, destacando os principais problemas encontrados.

\subsubsection{Fluxograma do processo da Fase 1}

A empresa de comércio eletrônico estudada tinha três bandeiras independentes para a comercialização de seus produtos, e cada uma delas possuía um centro de distribuição de revenda específico. Inicialmente, o processo de logística reversa era realizado dentro dos próprios centros de distribuição da revenda em uma área específica destinada à operação de reversa, sendo a gestão de todo o processo realizada pela própria empresa.

A Figura 6 retrata a fase 1 do processo de logística reversa. Todos os produtos retornados classificados como avariados eram encaminhados para estoque e depois eram reavaliados e reclassificados.

Nesta fase, o cliente solicitava o pedido de devolução do produto, alegando seus motivos. Assim que autorizado pelo SAC, o produto era recolhido e levado para o centro de distribuição (CD). Na entrada, era realizado o cadastramento do produto e ocorria a liberação do crédito, produto ou devolução do dinheiro para o cliente. Antes da armazenagem no estoque, era realizada apenas uma triagem simples, pela qual os produtos eram classificados como bom para revenda (WB) ou avariado (WA). Quando classificados como WB, eram encaminhados para o

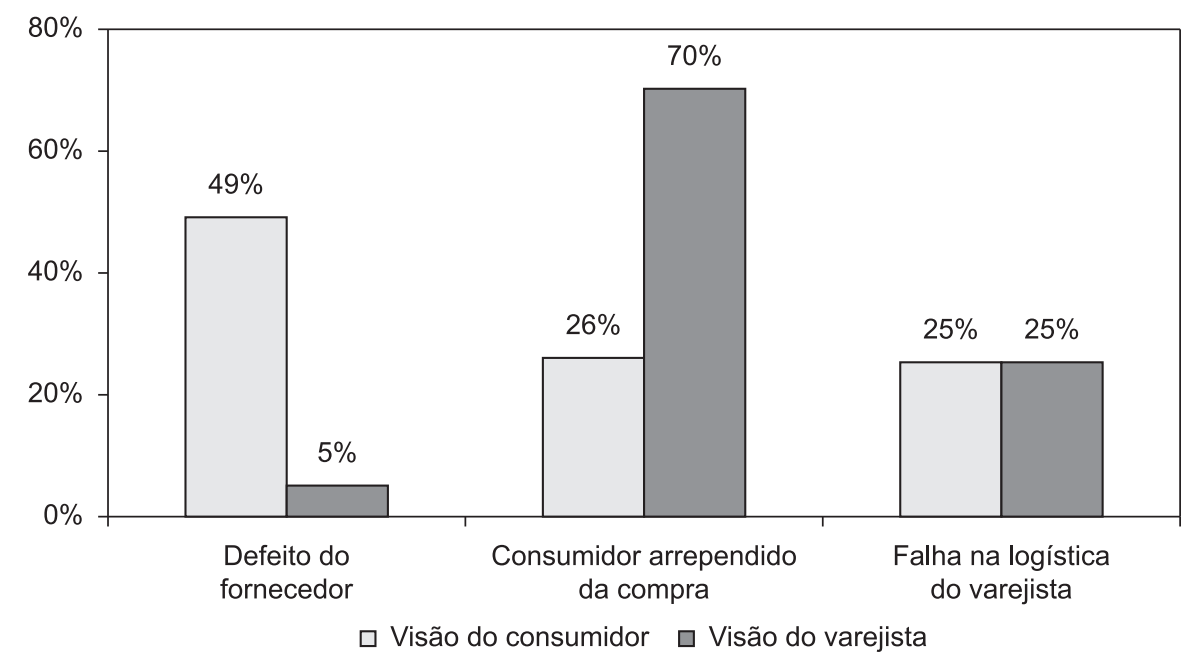

Figura 5. Comparativo entre as visões do consumidor e do varejista sobre os motivos de devolução. Fonte: A empresa. 


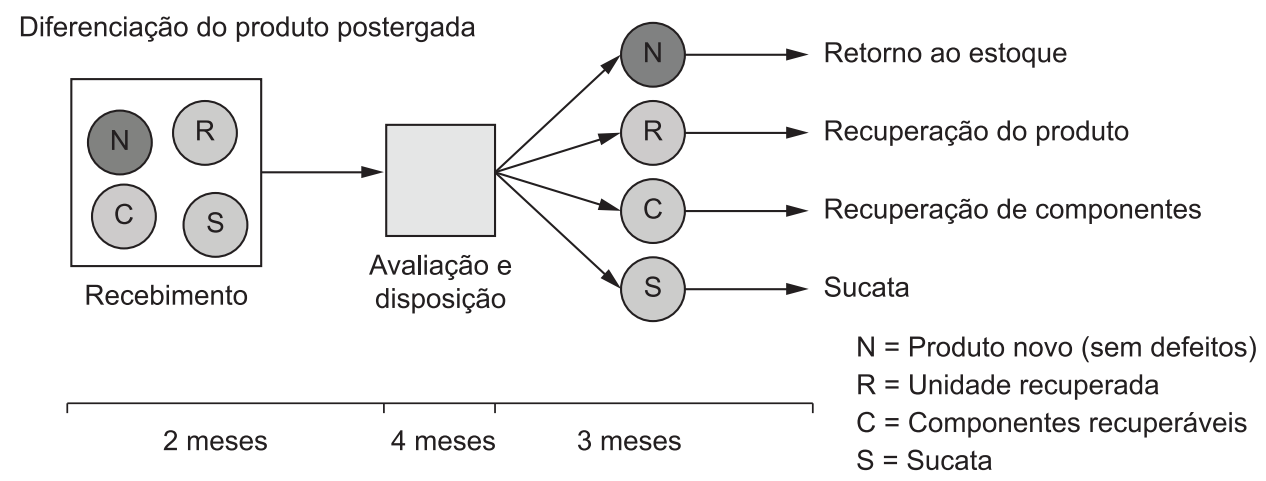

Figura 6. Macroprocesso da logística reversa de cada centro de distribuição. Fonte: Os autores.

estoque de produtos novos e, quando enquadrados como WA, eram armazenados em uma área segregada denominada: Informática, livros, eletrônicos, entre outros, aguardando as negociações com os respectivos fabricantes e assistências técnicas na tentativa de se conseguir os reparos necessários e/ou devoluções. $\mathrm{Na}$ estocagem, os produtos devolvidos eram agrupados por ordem de chegada e direcionados para armazenagem onde houvesse espaço livre nas áreas de segregação, tornando difícil seu rastreamento posterior, pois, em um mesmo palete, havia diversas categorias de itens. O fluxograma da Figura 7 retrata todos esses passos detalhadamente.

O critério para avaliação de reparos era único: o custo do conserto deveria ser baixo o suficiente de forma a garantir que, ainda após a tratativa, a empresa conseguisse obter a margem de lucro pré-estabelecida.

A empresa trabalhava com o conceito de estoques internos e externos. No processamento, não havia um controle eficiente dos itens localizados em áreas externas, os itens eram enviados para assistências técnicas (ATs) e sumiam do sistema, dificultando a rastreabilidade dos produtos após sua saída do CD. Esse fato gerou diversas perdas de produtos ao longo do processo, principalmente devido ao estoque real da ATs não ser compatível com o estoque registrado pelo sistema da empresa de comércio eletrônico.

Assim que os produtos retornavam da assistência técnica, havia uma nova classificação: os produtos considerados bons eram reintegrados ao estoque de revenda junto aos produtos novos e os que retornavam ainda com pequenos defeitos ou não reparados eram encaminhados para armazenagem na área de saldão, e depois eram revendidos com valor de $60 \%$ do preço do custo, ou encaminhados para a área de armazenagem de sucata, esperando para serem vendidos a preços muito baixos ( $20 \%$ do preço de custo).

Os principais problemas identificados neste processo da fase 1 foram:

- Triagem não eficaz;

- Armazenagem feita sem critério (exemplo: separação por família de produtos);
- Alto índice de avarias devido à falta de espaço, movimentações desnecessárias e manuseio inadequado dos produtos; e

- Falta de controle dos itens enviados às ATs e aos fornecedores.

\subsubsection{Fluxograma do processo da Fase 2}

Devido à falta de espaço e ao alto número de avarias resultantes do manuseio inadequado dentro dos armazéns de revenda, a empresa decidiu terceirizar o processo para um operador logístico, com a intenção de criar um estoque único de produtos provenientes da logística reversa para todas as suas três lojas virtuais. Os ganhos esperados eram definir melhor o processo e aproximar as áreas de negociações com a operação.

A Figura 8 retrata esta segunda fase do processo de logística reversa.

Nesta fase, o varejista terceirizou a atividade de logística reversa para um operador logístico dedicado. A primeira decisão foi unificar todo o estoque proveniente das três bandeiras em outro CD centralizado, porém separado fisicamente dos estoques de revenda de cada bandeira.

No recebimento, começou a ser elaborado um laudo de cada produto; em seguida, os produtos passam por uma verificação de restrições, sendo classificados como bom para revenda (WB) ou produto com avaria (WA). Os produtos considerados WB ficam no armazém, apenas esperando para serem enviados ao centro de distribuição da revenda, enquanto os produtos WA passam novamente por uma análise interna feita por técnicos especialistas (externos), sendo avaliados como produtos para saldão (WS), sucata ou avariados (WA). Os itens considerados WA são encaminhados para a área destinada de armazenagem e aguardam as negociações com os fornecedores e assistências técnicas para receberem as tratativas necessárias (devolução para o fornecedor ou envio para assistência técnica).

O critério de avaliação da viabilidade de reparos é similar ao primeiro processo, porém o que difere 


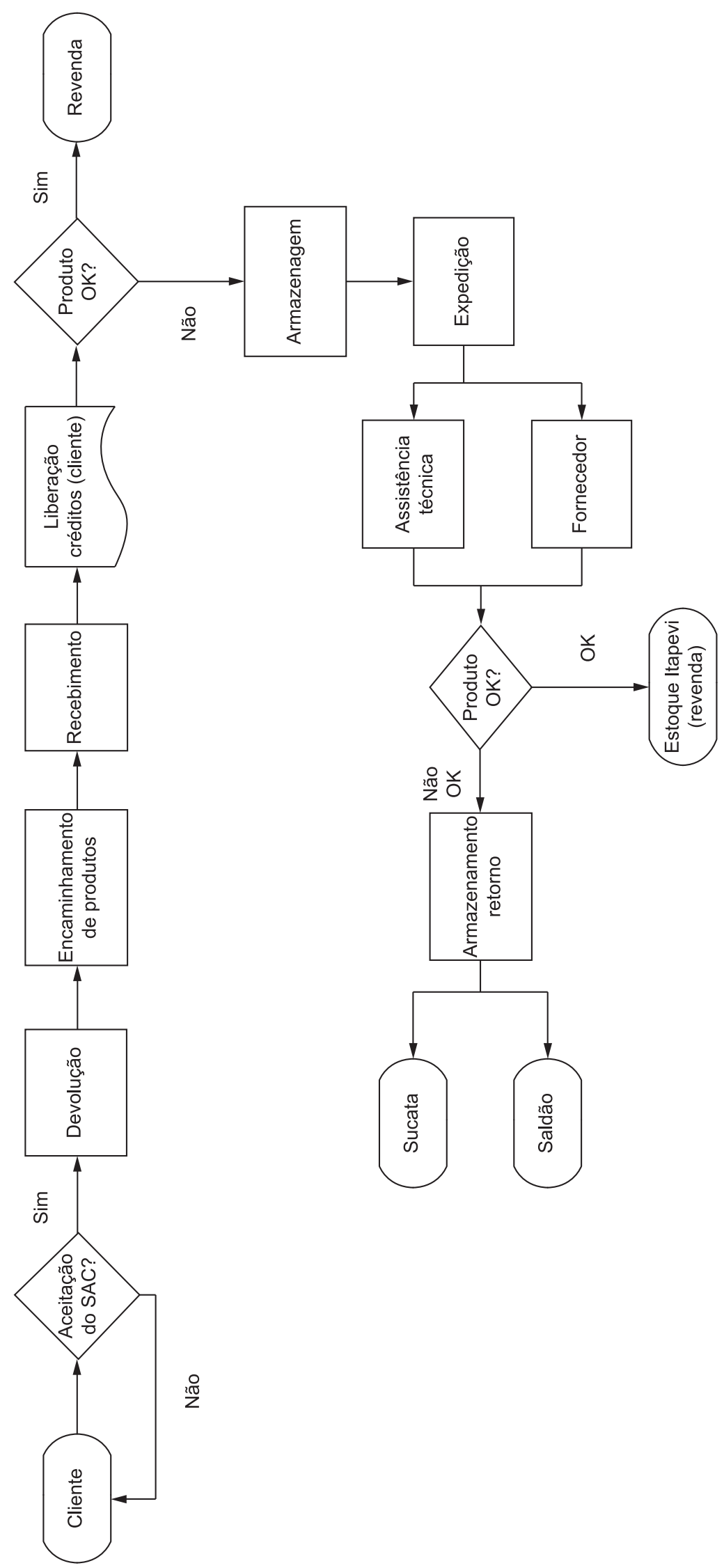

Figura 7. Fluxograma primeira fase do processo. Fonte: Autores (baseado nas informações fornecidas pela empresa). 
Diferenciação do produto adiantada

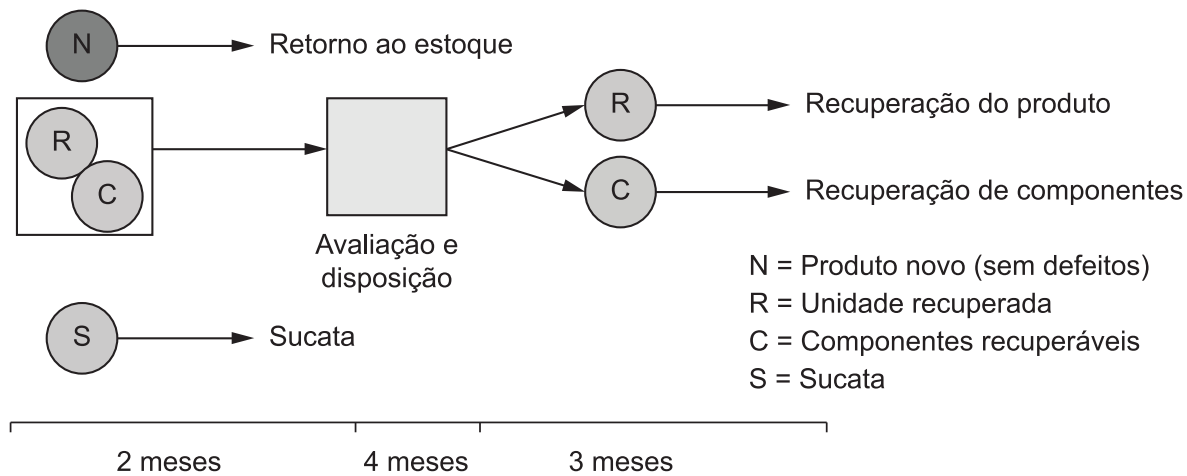

Figura 8. Macroprocesso na fase de terceirização do processo de logística reversa. Fonte: Os autores.

neste segundo momento é a classificação quanto ao retorno da assistência técnica e fornecedor (são enquadrados apenas como WB ou WS), visto que, na análise interna, os produtos classificados como sucata nem chegam a sair do $\mathrm{CD}$, diferentemente do primeiro processo, quando os produtos só eram classificados como sucata após retornarem das ATs ou fornecedor.

As políticas adotadas no primeiro período eram: identificar os problemas e solicitar mais consertos e coberturas de perdas dos fornecedores, controlar melhor o envio dos produtos para as assistências técnicas e/ou fornecedores e trabalhar nas negociações de venda do saldão.

A armazenagem ainda era realizada de acordo com a disponibilidade de espaço nos porta-paletes, sendo o único critério de segregação existente a separação por bandeira, o que continuava a dificultar a situação, devido ao elevado número de SKU (unidades mantidas em estoque).

Este processo ainda apresenta problemas, tais como:

- armazenagem feita sem critério (exemplo: separação por fornecedor);

- perda de valor dos produtos devido ao elevado lead time do processo.

O processo adotado na fase 2 é representando pelo fluxograma da Figura 9.

\subsubsection{Fluxograma do processo da Fase 3}

A ideia central deste novo modelo de gestão é aplicar uma tratativa diferenciada aos produtos que retornam, mas que não apresentam defeitos ou avarias, e para revendê-los como open box diretamente ao consumidor, ao invés de direcionar produtos usados para mercados secundários e sucatas.

O processo desta terceira fase pode ser representado pela Figura 10.

No recebimento, os produtos sofrem uma triagem inicial para a separação por bandeira/loja e, em seguida, a classificação como WB (bom para revenda), outlet (produtos open box que não apresentam avarias ou defeitos) e WA (produtos avariados). A partir de então, o fluxo do processo continua idêntico ao anterior, exceto no que diz respeito ao volume de itens enviados para a assistência técnica, pois foi instalada dentro do próprio $\mathrm{CD}$ da logística reversa uma equipe técnica própria interna, especializada em reparos, que é responsável pela triagem/diagnóstico mais detalhado dos produtos e que também faz pequenos reparos, reduzindo assim a quantidade de produtos que saem do CD para reparos (estoque externo).

Também foi colocado em prática um modelo de melhoria em relação à armazenagem dos itens, pois, além do critério da separação por bandeira, os produtos agora são agrupados também por fornecedor, o que facilita sua localização. Foi posto em prática o conceito de ruas de maior giro, em que ficam estocados, próximos da saída, aqueles produtos que têm mais saída.

A adoção deste modelo trouxe uma redução de custos de transporte para o varejista do mercado eletrônico devido à diminuição do volume de saída para as assistências técnicas, menor movimentação dos itens, evitando avarias durante o processo de logística reversa, além de redução do backlog proveniente das assistências técnicas. A ideia é proporcionar mais velocidade e agilidade ao processo como um todo e, consequentemente, redução dos custos com armazenagem. Além disso, foi obtida uma receita maior referente à venda dos produtos no site com menores taxas de descontos (sem grande perda de valor). Anteriormente os produtos eram revendidos em saldões com $50 \%$ de desconto, sendo agora revendidos com desconto de $20 \%$ ao consumidor final.

O processo detalhado é representando pelo fluxograma da Figura 11.

O modelo tem como principal característica a diminuição da incidência de reparo externo dos produtos, sendo todos os produtos apenas classificados 


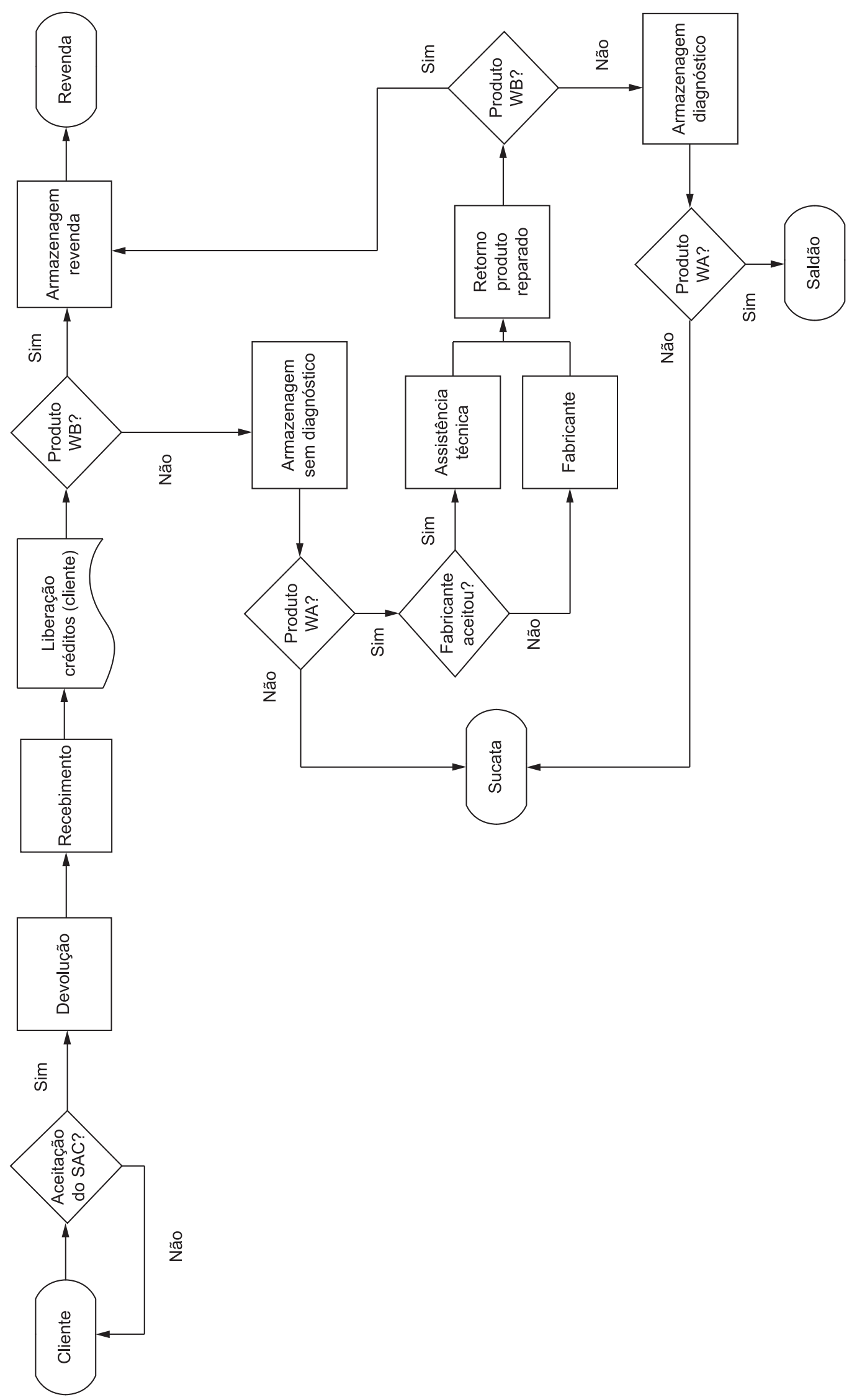

Figura 9. Fluxograma do processo atual. Fonte: Autores (baseado nas informações fornecidas pela empresa). 
Diferenciação do produto adiantada e venda direta

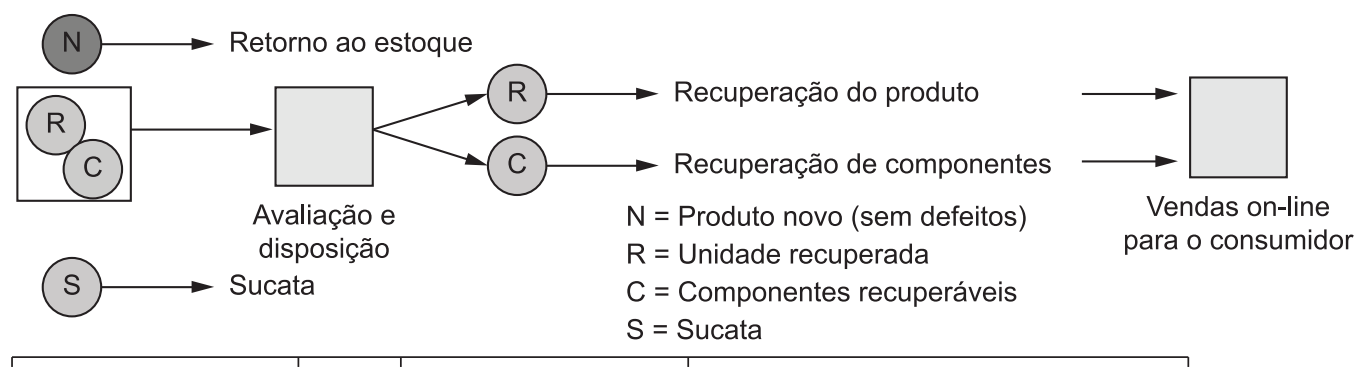

2 meses $\quad 4$ meses $\quad 3$ meses

Figura 10. Macroprocesso do novo processo de logística reversa. Fonte: Os autores.

internamente de acordo com suas avarias. Outro diferencial relevante é o controle realizado por sistema computacional neural integrado, o qual faz o controle e o rastreamento do produto, desde sua entrada até sua saída do processo.

Terminado o processo de triagem, ocorre a avaliação de especialistas de acordo com o funcionamento do produto, sendo realizada também a avaliação da embalagem. Com o preenchimento das avaliações, é emitido um laudo que caracteriza o produto no sistema. O produto é encaminhado para a armazenagem somente após a certificação do laudo e a realização dos reparos.

Habitualmente, os produtos são classificados e armazenados por SKUs, porém, neste novo modelo, devido ao processo de triagem, o cadastramento é feito por unidade de itens, tendo suas características ligadas ao laudo emitido previamente na etapa da triagem. Desse modo, a armazenagem é feita em paletes e caixas plásticas para facilitar o rastreamento, além de evitar erros em sua separação.

A saída do produto ocorre somente por meio do site de revenda da empresa. Nele, o cliente, após realizar seu cadastro pessoal, tem acesso ao laudo do reparo e precificação do produto, podendo desse modo efetuar a compra. Feito o pedido, dá-se início ao processo de expedição. O sistema solicita a separação do produto e ocorre sua conferência, segundo as especificações cadastrais da triagem. Ao obter a confirmação positiva da conferência, é autorizada a expedição.

A proposta deste modelo é fazer com que o varejista possa recuperar receita com o estoque parado de produtos retornados que, depois de um tempo, acabariam tendo como destino a sucata.

Hoje, quando a empresa vende esse estoque de retornados para descarte ou para um leilão, consegue de $10 \%$ a $20 \%$ do custo médio de venda (CMV); isso significa, na melhor das hipóteses, que perdeu $80 \%$ do CMV, o que representa prejuízo, já que o produto entrou na contabilidade dele a $100 \%$ e está saindo a $20 \%$.
O canal de venda especializado em produtos usados transforma os $20 \%$ de CMV em $60 \%$, esse é o grande foco de negócio para o comércio eletrônico da Reversa (Gerente de Consumer \& E-commerce).

\subsection{Análise e discussão}

Alguns estudos já mostraram a importância de uma política de retorno transparente, bem como de uma estratégia de disposição do produto retornado bem definida, como oportunidades para obtenção de vantagens competitivas e melhor desempenho no varejo (SKINNER; BRYANT; RICHEY, 2008). O caso estudado desta pesquisa mostra a evolução do processo de logística reversa do varejista virtual. O Quadro 4 apresenta um comparativo das características das diferentes fases do processo de logística reversa da empresa estudada.

Na fase 1 a empresa possuía um modelo de gestão próprio descentralizado, cada bandeira de loja virtual era responsável por sua própria logística reversa. Os produtos avariados eram recebidos, armazenados e depois sofriam uma triagem para sua classificação em sucata ou saldão. Nesta situação a triagem não era eficaz, a armazenagem feita sem critério e o manuseio excessivo.

$\mathrm{Na}$ Fase 2, foram introduzidas as seguintes melhorias: a logística reversa para as três bandeira foi centralizada, a operação foi terceirizada para um operador logístico e principalmente a empresa melhorou sua operação de triagem. Logo no recebimento o produto passou a ser classificado como livre de defeitos (retorno ao estoque), avariado sucata e avariado necessitando de avaliação da assistência técnica. Neste processo, os produtos classificados como sucata não são direcionados para a assistência técnica. Isso economiza tempo e reduz custos.

$\mathrm{Na}$ fase 3, foram introduzidas as seguintes novidades: a instalação de um posto de assistência técnica dentro do próprio $\mathrm{CD}$ da logística reversa, eliminando os custos de transporte e armazenagem, 


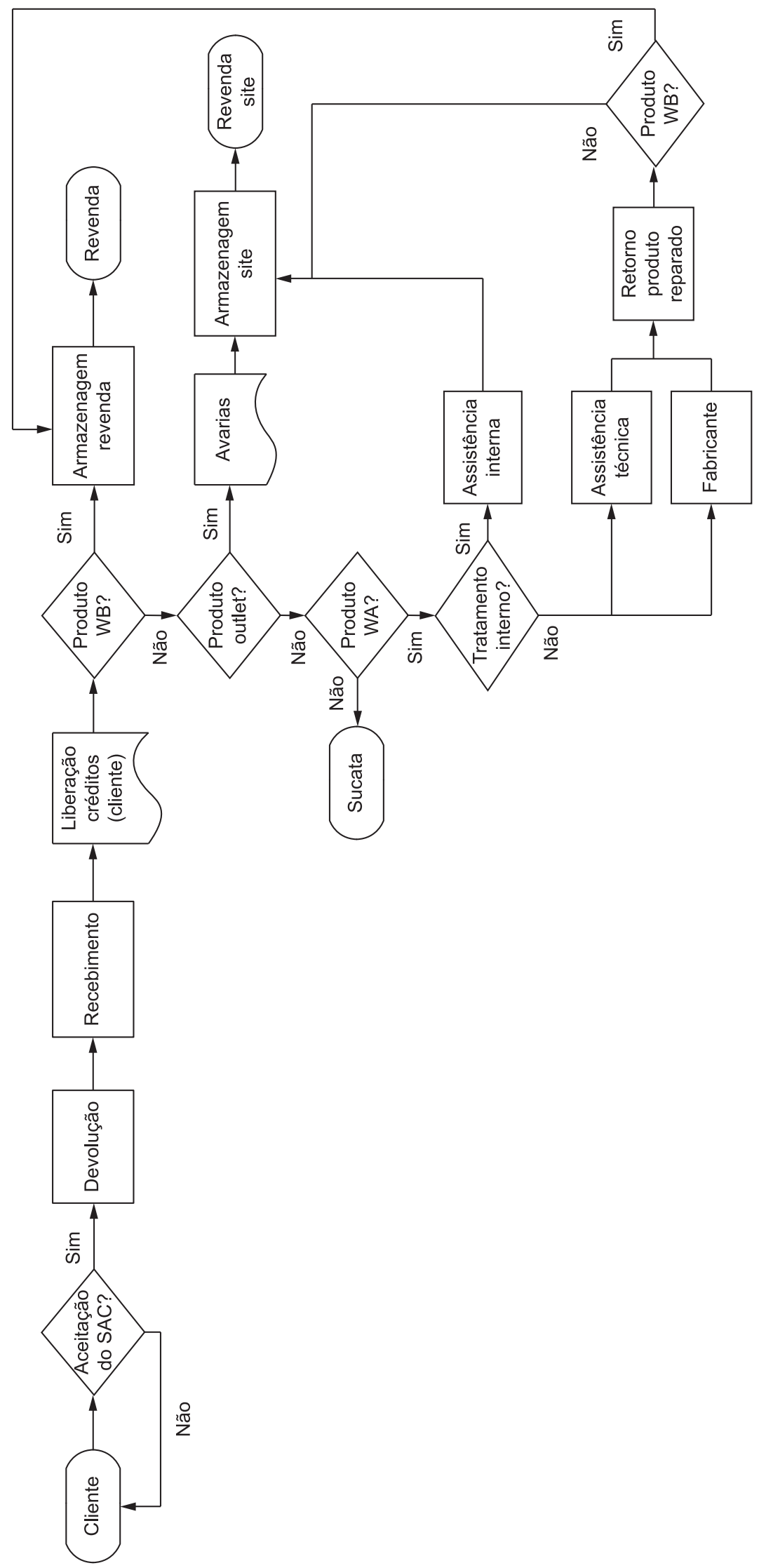

Figura 11. Fluxograma do novo processo. Fonte: Autores (baseado nas informações fornecidas pela empresa). 
Quadro 4. Comparativo entre as diferentes fases do processo de logística reversa.

\begin{tabular}{|c|c|c|c|c|}
\hline \multirow[t]{2}{*}{ Fases } & \multicolumn{4}{|c|}{ Etapas } \\
\hline & Triagem & Armazenagem & Expedição & Tratativas \\
\hline 1 & $\begin{array}{l}\text { Classificação dos } \\
\text { produtos em: } \\
\text { WB: produtos bons } \\
\text { para revenda. } \\
\text { WA: produtos com } \\
\text { avarias. }\end{array}$ & $\begin{array}{l}\text { Produtos agrupados } \\
\text { em paletes por ordem } \\
\text { de chegada, sem } \\
\text { critério de segregação } \\
\text { e estocados nas ruas } \\
\text { do CD. }\end{array}$ & $\begin{array}{c}\text { Assistência técnica } \\
\text { (AT) externa } \\
\text { 100\% dos produtos WA } \\
\text { são enviados às ATsou } \\
\text { fornecedores. }\end{array}$ & $\begin{array}{l}\text { Produtos WB revendidos como } \\
\text { novos. } \\
\text { Produtos retornados de ATs } \\
\text { e considerados WB são } \\
\text { reintegrados ao estoque de } \\
\text { revenda. } \\
\text { Produtos retornados de ATs e } \\
\text { considerados WA são vendidos } \\
\text { em saldões ou como sucata. }\end{array}$ \\
\hline 2 & $\begin{array}{c}\text { Classificação dos } \\
\text { produtos em: } \\
\text { WB: produto bom para } \\
\text { revenda. } \\
\text { WA: produtos com } \\
\text { avarias.WS: produtos } \\
\text { danificados. }\end{array}$ & $\begin{array}{l}\text { Produtos agrupados } \\
\text { por bandeira/loja em } \\
\text { paletes por ordem de } \\
\text { chegada e estocados } \\
\text { em prateleiras. }\end{array}$ & $\begin{array}{c}\text { Assistência técnica } \\
\text { externa. } \\
\text { Produtos WS vão para } \\
\text { vendas desaldão. } \\
\text { Produtos WA são } \\
\text { enviados para as ATs. }\end{array}$ & $\begin{array}{l}\text { Produtos WB revendidos como } \\
\text { novos. } \\
\text { Produtos retornados de ATs } \\
\text { e considerados WB são } \\
\text { reintegrados ao estoque de } \\
\text { revenda. } \\
\text { Produtos retornados de ATs e } \\
\text { considerados WA são vendidos } \\
\text { em saldões ou como sucata. }\end{array}$ \\
\hline 3 & $\begin{array}{l}\text { Classificação dos } \\
\text { produtos em: } \\
\text { WB: produto bom para } \\
\text { revenda. } \\
\text { WA: produto pouco } \\
\text { avariado. } \\
\text { WS: produto muito } \\
\text { avariado. }\end{array}$ & $\begin{array}{c}\text { Produtos agrupados } \\
\text { por bandeira/loja e por } \\
\text { fornecedor, sendo os } \\
\text { produtos de maior giro } \\
\text { estocados nas ruas mais } \\
\text { acessíveis. }\end{array}$ & $\begin{array}{l}\text { Assistência técnica } \\
\text { interna e externa. } \\
\text { Produtos WA com } \\
\text { avarias mínimas são } \\
\text { tratados dentro dos } \\
\text { CDs, o restante é } \\
\text { enviado para as ATs. } \\
\text { Produtos WS são } \\
\text { enviados para estoque } \\
\text { de venda de saldão. }\end{array}$ & $\begin{array}{c}\text { Produtos WB revendidos como } \\
\text { novos. } \\
\text { Produtos Outlets são vendidos } \\
\text { através do site de venda de } \\
\text { logística reversa. } \\
\text { Produtos retornados de ATs } \\
\text { e considerados WB são } \\
\text { reintegrados ao estoque de } \\
\text { revenda. } \\
\text { Produtos retornados de ATs e } \\
\text { considerados WA são vendidos } \\
\text { em saldões ou como sucata. }\end{array}$ \\
\hline
\end{tabular}

Fonte: Os autores.

criação do canal on-line para revenda direta ao consumidor dos produtos avariados, mas que mantém sua funcionalidade intacta. Este procedimento permitiu maior recuperação de valor do produto do que a venda por leilões que vigorava até então.

Outro aspecto relevante da gestão do processo de logística reversa que pode ser ressaltado na organização estudada é a formalização. Segundo Genchev et al. (2011), a formalização de processos mais complexos como o de logística reversa pode se tornar um fator diferencial na sua implementação e desenvolvimento. A formalização pode auxiliar a organização a melhor gerenciar suas operações na logística reversa e, pode ser implementada por meio de diversas ferramentas, tais como políticas escritas, procedimentos documentados, descrição de tarefas/atividades, fluxogramas, ou qualquer outra forma adequada à operação. A evolução do processo no caso estudado foi efetivamente facilitada no seu desenvolvimento e implementação pela existência de instruções escritas e fluxogramas, que serviram de base para o treinamento do pessoal envolvido e avaliação do desempenho do processo. Genchev et al.
(2011), reforçam a importância da análise dos retornos e avaliação do desempenho do processo por meio de indicadores como taxa de retorno, tipo de produtos retornados, valor dos retornos, porcentagem das vendas e tempo de ciclo, os quais são já utilizados na organização estudada.

Outros estudos identificaram ainda outras oportunidades para redução de custos no processo de logística reversa, como a adoção de medidas preventivas para reduzir a quantidade de retornos (LAMBERT; CROXTON; GARCÍA-DASTUGUE, 2008). Os dados da organização estudada mostram substancial disparidade entre os motivos de devolução na perspectiva dos consumidores e do varejista, o que pode indicar oportunismo do consumidor na sua relação com o varejista (JACK; POWERS; SKINNER, 2010). Medidas preventivas, tais como atividades promocionais de esclarecimento aos consumidores, modificações no projeto de produtos e melhores instruções de uso dos produtos, poderiam ser adotadas para reduzir o número de retornos. 


\section{Conclusões}

Este trabalho teve como objetivo descrever e avaliar a evolução do processo de logística reversa de um importante varejista do mercado brasileiro de comércio eletrônico, identificando as mudanças estratégicas realizadas, problemas e soluções encontradas, bem como estatísticas do atual processo LReC e tendências futuras do setor. Visando alcançar esse objetivo de maneira assertiva, foram desenvolvidas questões de pesquisa e proposições relativas a estas.

A primeira questão procurava investigar a evolução dos processos de logística reversa da empresa. Para responder a esta questão foi necessário levar em consideração que o volume de produtos vendidos por meio do comércio eletrônico aumentou consideravelmente nos últimos anos e, consequentemente, o fluxo reverso acompanhou esse crescimento. À medida que o comércio eletrônico cresce, as devoluções também devem crescer de maneira mais acentuada, considerando que o consumidor brasileiro tem ficado cada vez mais exigente. Logo, os processos de logística reversa da empresa sofreram mudanças ao longo do tempo para se adequar a essa realidade. No caso estudado, o varejista de comércio eletrônico migrou de um CD compartilhado com a logística direta para um CD exclusivo de logística reversa, terceirizando o gerenciamento do processo reverso. A proposição 1 se confirma uma vez que foram constatadas mudanças significativas no processo de logística reversa decorrentes do aumento de volume, no caso estudado. Pode-se afirmar que uma tendência futura para o mercado seja mudar para um modelo de gestão de logística reversa multiclientes, ou seja, para o setor como um todo e não mais dedicado exclusivamente para uma única empresa, representando uma economia de escala.

A segunda questão de pesquisa referia-se à taxa de retorno e aos motivos de devoluções dos produtos adquiridos pelo comércio eletrônico. Foi constatado que a taxa de retorno corresponde a cerca de 3\% a 4\% do faturamento e, que as principais causas de devolução são produtos com defeitos ou que não atenderam às expectativas do consumidor, arrependimento e falhas logísticas. Existem duas perspectivas quando se trata de devoluções: a do consumidor e a do fabricante. Segundo o consumidor, o maior motivo de devolução dos produtos é a presença de defeitos, chegando a quase $50 \%$ dos casos, porém os fabricantes alegam que apenas 5\% desses produtos realmente apresentam algum tipo de defeito. De acordo com os entrevistados, a possível explicação é a falta de conhecimento do consumidor em relação à utilização dos produtos, evidenciando a necessidade de criação de uma política de retenção do retorno dos produtos mais elaborada, porém sem ferir o direito do consumidor ou criar no cliente a sensação de insatisfação em função da dificuldade em devolver um produto. Fica claro que é preciso desenvolver uma ferramenta de apoio ao cliente no pós-venda, como, por exemplo, desenvolver um script com instruções dos produtos com maiores índices de retorno e treinar os funcionários para executá-lo junto ao cliente no momento em que este sinaliza a intenção de devolução. $O$ site de venda também é pobre em orientar o consumidor de possíveis erros de compras, por exemplo, voltagem. O sistema poderia automaticamente identificar o IP do comprador e confirmar a voltagem do produto adquirido. Este conceito de duplo check deveria ser incorporado aos processos de vendas para evitar retornos desnecessários. A proposição em relação a esta questão de pesquisa foi parcialmente confirmada: a taxa de retorno de uma empresa de comércio eletrônico no Brasil é inferior à taxa de retorno de uma empresa de comércio eletrônico de participação de mercado semelhante em países desenvolvidos. Porém os produtos retornam, principalmente, devido ao arrependimento da compra do consumidor.

Em relação à terceira questão, foi possível verificar que o processo de logística reversa de produtos vendidos por meio do comércio eletrônico apresenta as seguintes deficiências principais: muitos produtos retornam de forma indevida ou sem necessidade; após o retorno, os produtos são triados de forma inadequada e sem controle de gestão e efetividade; e o tempo excessivo no processo de recuperação de valor do produto. Considerando esse cenário, existe oportunidade para o desenvolvimento de iniciativas que reduzam o retorno de produtos e melhorem o tempo de processamento do retorno e controle dos gastos, garantindo a efetividade dos reparos, minimizando irregularidades e agregando valor aos produtos retornados no processo de recuperação.

A proposição 3 se confirma, uma vez que as principais deficiências identificadas repercutem no tempo de processamento e acarretam perdas financeiras como, por exemplo, os altos custos de transporte e armazenagem.

É importante ressaltar que este trabalho apresenta limitações, pois o estudo de caso foi realizado em apenas uma empresa, que, apesar de possuir um market share de aproximadamente $40 \%$ do mercado de comércio eletrônico brasileiro, constitui ainda assim um único caso. Considerando esse fato, as soluções de logística reversa mencionadas neste trabalho podem não se aplicar em todos os tipos de empresas, assim como os dados aqui apresentados podem não refletir a realidade do mercado de pequenas e médias empresas.

\section{Futuras pesquisas}

Várias oportunidades para pesquisas futuras podem ser mencionadas a partir do caso apresentado. A primeira seria estender a pesquisa a outros varejistas, 
incluindo aqueles não só com operações virtuais, mas também com operações mistas, o que poderia trazer novos conhecimentos sobre o processo de logística reversa para acadêmicos e profissionais.

O impacto de outros aspectos da operação de logística reversa, como, por exemplo, a transparência da política de retornos, as estratégias de disposição de produtos retornados e a influência das capacidades logísticas no comércio eletrônico, também necessitam de estudos mais aprofundados que poderiam ser desenvolvidos em novas pesquisas.

Outro campo ainda pouco explorado diz respeito ao processo de logística reversa na cadeia de suprimento, de forma a melhor entender o impacto das políticas e instrumentos de gestão na cadeia como um todo. Um estudo longitudinal poderia auxiliar nesse entendimento.

\section{Referências}

AGRAWAL, A. Turn your reverse supply chain into a profit center. CSCMP Supply Chain Quarterly, Q1, 2012.

ALBERTIN, A. L. Comércio eletrônico: modelo, aspectos e contribuições de sua aplicação. 6. ed. São Paulo: Atlas, 2010.

BRASIL. Congresso Nacional. Código de Proteção e Defesa do Consumidor (Lei 8.078, de 11/09/1990). ed. rev., atual. ampl. Brasília, 2011. 28 p.

CORREA, H. L. Gestão de redes de suprimentos. São Paulo: Atlas, 2010.

COUNCIL OF SUPPLY CHAIN MANAGEMENT PROFESSIONAL - CSCMP. Glossary of terms. CSCMP, 2010. Disponível em: <http://cscmp.org/ digital/glossary/glossary.asp>. Acesso em: 24 fev. 2012.

EISENHARDT, K. M. Building theories from case study researches. Academy of Management Review, v. 14, n. 4, p. 532-550, 1989.

ELLRAM, L. M. The use of the case study method in logistics research. Journal of Business Logistics, v. 17, n. 2, p. 93-138, 1996.

GENCHEV, S. E.; RICHEY, R. G.; GABLER, C. B. Evaluating reverse logistics programs: a suggested process formalization. The International Journal of Logistics Management, v. 22, n. 2, p. 242-263, 2011. GEORGIADIS, P.; VLACHOS, D. The effect of environmental parameters on product recovery. European Journal of Operational Research, v. 157, n. 2, p. 449-464, 2004. http://dx.doi.org/10.1016/S0377-2217(03)00203-0

JACK, E. P.; POWERS, T. L.; SKINNER, L. Reverse logistics capabilities: antecedents and cost savings. International Journal of Physical Distribution \& Logistics Management, v. 40, n. 3, p. 228-246, 2010. http://dx.doi.org/10.1108/09600031011035100

LAMBERT, D. M. et al.The return management process. The International Journal of Logistics Management, v. 13, n. 2, p. 1-18, 2002. http://dx.doi. org/10.1108/09574090210806397
LAMBERT, D. M.; CROXTON, K. L.; GARCÍADASTUGUE, S. J. The role of logistics managers in the cross-functional implementation of supply chain management. Journal of Business Logistics, v. 29, n. 1, p. 113-133, 2008. http://dx.doi. org/10.1002/j.2158-1592.2008.tb00071.x

LAMBERT, D. M. Supply chain management: processes, partnerships, performance. 3. ed. Sarasota: Supply Chain Management Institute, 2008. p.147-166.

LEITE, P. R. Logística reversa: meio ambiente e competitividade. São Paulo: Prentice Hall, 2009.

KNEBEL, P. Logística reversa: empresas têm desafio de administrar devoluções. Jornal do Comércio, Poa, 11 jul. 2009. Disponível em: <http://www.ecommerce.tv.br/ logistica-reversa-empresas-tem-desafio-de-administrardevolucoes/>. Acesso em: 17 fev. 2012.

KOKKINAKI, A. I. et al. An exploratory study on Electronic commerce for RL. Econometric Institute Report EI 9950/A, Erasmus University of Rotterdam, The Netherlands, 1999

KRUMWIEDE, D. W.; SHEU, C. A model for reverse logistics entry by third-party providers. The International Journal of Management Science, v. 30, p. 325-333, 2002.

MARTINS, V. M. A. Logística Reversa no Brasil: estado da arte. 2005. 146 f. Tese (Doutorado em Administração)Faculdade de Administração, Universidade Federal do Rio de Janeiro, Rio de Janeiro, 2005.

McCULLOUGH, S. S. Mastering commerce logistics. Cambridge: Forrester Research, 1999.

NOVAES, A. G. Logística e gerenciamento da cadeia de distribuição. Rio de Janeiro: Campus, 2007.

ROGERS, D. S.; TIBBEN-LEMBKE, R. S. Going backwards: reverse logistics trends and practices. Reno: University of Nevada, 1999.

ROGERS, D. S.; TIBBEN-LEMBKE, R. An examination of reverse logistics practices. Journal of Business Logistics, v. 22, n. 2, p. 129-148, 2001. http://dx.doi. org/10.1002/j.2158-1592.2001.tb00007.x

SCHULTMANN, F.; ZUMKELLER, M. Modeling reverse logistic tasks within closed-loop supply chains: an example from the automotive industry. European Journal of Operational Research, v. 171, n. 3, p. 1033-1050, 2006. http://dx.doi.org/10.1016/j.ejor.2005.01.016

SKINNER, L. R.; BRYANT, P. T.; RICHEY, R. G. Examining the impact of reverse logistics disposition strategies. International Journal of Physical Distribution \& Logistics Management, v. 38, n. 7, p. 518-539, 2008. http://dx.doi.org/10.1108/09600030810900932

STOCK, J. R. Development and implementation of reverse logistics programs. Council of Logistics Management, 1998.

STOCK, J. R.; MULKI, J. P. Product returns processing: an examination of practices of manufacturers, wholesalers/ distributors, and retailers. Journal of Business Logistics, n. 30, v. 1, p. 33-52, 2009. http://dx.doi. org/10.1002/j.2158-1592.2009.tb00098.x

YIN, R. K. Case study research: design and methods. 3rd ed. Califórnia: Sage Publications, 2003. 